\title{
One-Level Versus 2-Level Treatment With Cervical Disc Arthroplasty or Fusion: Outcomes Up to 7 Years
}

\author{
MATTHEW F. GORNET, MD, ${ }^{1}$ TODD H. LANMAN, MD, ${ }^{2}$ J. KENNETH BURKUS, MD ${ }^{3}$ SCOTT D. HODGES, \\ DO ${ }^{4}$ JEFFREY R. MCCONNELL, MD,${ }^{5}$ RANDALL F. DRYER, MD,${ }^{6}$ FRANCINE W. SCHRANCK, BSN ${ }^{7}$ \\ ANNE G. COPAY, PHD \\ ${ }^{1}$ Orthopedic Center of St Louis, St Louis, Missouri, ${ }^{2}$ California Spine Group, Century City Hospital, Los Angeles, California, ${ }^{3}$ Wilderness Spine Services, \\ Columbus, Georgia, ${ }^{4}$ Center for Sports Medicine and Orthopedics, Chattanooga, Tennessee, ${ }^{5}$ Orthopedic Associates of Allentown, Allentown, Pennsylvania \\ ${ }^{6}$ Central Texas Spine Institute, Austin, Texas, ${ }^{7}$ SPIRITT Research, St Louis, Missouri, ${ }^{8}$ SPIRITT Research, St Louis, Missouri
}

\begin{abstract}
Background: Anterior cervical discectomy and fusion (ACDF) and cervical disc arthroplasty (CDA) have been used to treat degenerative disc disease at single as well as multiple cervical levels. This study compares the safety and efficacy of 1-level versus 2-level CDA and ACDF.

Methods: In total, 545 and 397 patients with degenerative disc disease were studied in 1-level and 2-level Food and Drug Administration (FDA)-approved clinical trials, respectively: CDA ( $\mathrm{n}=280$ and 209), ACDF ( $\mathrm{n}=265$ and 188). Data from these studies were used to compare 1- versus 2-level procedures: the propensity score method was used to adjust for potential confounding effects, and adjusted mean outcome safety and efficacy scores at 2 and 7 years postsurgery were compared between 1-level and 2-level procedures within treatment type.

Results: One-level and 2-level procedures had similar rates of improvement in overall success and patient-reported outcomes scores for both CDA and ACDF. There were no statistical differences in rates of implant-related adverse events (AEs) or serious implant-related AEs between 1-level and 2-level CDA. The 7-year rate of implant-related AEs was higher for 2-level than 1-level ACDF (27.7\% vs $18.9 \%, P \leq .036)$, though the rates of serious implant-related AEs between ACDF groups did not differ significantly. Secondary surgery rates were not statistically different between 1level and 2-level procedures (CDA or ACDF) at the index or adjacent levels at 2 or 7 years. Grade IV heterotopic ossification at 7 years was reported in $4.6 \%$ of 1 -level CDA patients and $8.6 \% / 7.3 \%$ at the superior/inferior levels, respectively, of 2-level CDA patients.

Conclusions: One- and 2-level CDA appear equally safe and effective in the treatment of cervical degenerative disc disease. Two-level ACDF appears to be as effective as 1-level ACDF but with a higher rate of some AEs at longterm follow-up.

Level of Evidence: 2.

Clinical Trials: clinicaltrials.gov: NCT00667459, NCT00642876, and NCT00637156.
\end{abstract}

Cervical Spine

Keywords: cervical disc arthroplasty (CDA), anterior cervical discectomy and fusion (ACDF), cervical disc disease

\section{INTRODUCTION}

Anterior cervical discectomy and fusion (ACDF) has been the traditional treatment for degenerative conditions of the cervical spine. Cervical disc arthroplasty (CDA) is an established safe and effective alternative treatment of cervical pathology. In the United States, CDA has been approved for use at a single level or 2 contiguous levels. To control for the surgical and biomechanical differences between single- and multilevel pathology, clinical trials have directly compared single-level ACDF to single-level $\mathrm{CDA}^{1-6}$ and multilevel ACDF to multilevel $\mathrm{CDA} .^{7-10}$
While most patients suffer from multilevel spine pathology, ${ }^{7}$ the safety and effectiveness of cervical surgery may be affected by the number of treated levels. Biomechanical studies have demonstrated that cervical fusion increases intradiscal pressure and segmental motion at the adjacent segments levels. ${ }^{11-13}$ More important, 2-level fusion can result in increased stress to the adjacent levels compared to 1-level fusion. ${ }^{12,13}$ These elevated stress levels are thought to contribute to early disc degeneration, osteophyte formation, and adjacent segment degeneration. Indeed, clinically symptomatic adjacent segment degeneration has been reported following cervical fusion. ${ }^{14-16}$ Multilevel ACDF, especially 
with more than 2 fused levels, is more likely to result in pseudoarthrosis. ${ }^{17}$ Finally, multilevel ACDF may result in more frequent and more extensive revision surgeries than single-level ACDF. ${ }^{18}$

Increasing the number of arthroplasty levels is also not without possible consequences. The negative effect of imperfect device positioning and endplate-device matching would likely be amplified in multilevel CDA. ${ }^{19,20}$ The incidence of heterotopic ossification (HO) has been found to increase with the number of cervical arthroplasty levels without affecting patient-reported outcomes. ${ }^{21,22}$ Further and stronger long-term evidence is still needed in order to evaluate multilevel cervical surgeries. ${ }^{20,23}$

In an effort to establish the impact of increased surgical levels on the outcomes of both CDA and $\mathrm{ACDF}$, a few studies have compared investigational and control arms within or across clinical trials so that 1-level CDA could be compared to 2-level CDA and 1-level ACDF compared to 2-level ACDF. ${ }^{24-26}$ These studies indicated comparable outcomes for 1level and 2-level CDA but a decrease in efficacy from 1-level to 2-level ACDF. The purpose of this study is to compare outcomes of 1-level CDA to 2level CDA and of 1-level ACDF to 2-level ACDF at 2 and 7 years in a relatively large number of patients enrolled in clinical trials involving the same devices and the same efficacy and safety measures for both the 1-level and the 2-level studies, thereby adding to the body of evidence.

\section{MATERIALS AND METHODS}

The data of 2 previously conducted Food and Drug Administration-approved Investigational Device Exemption (IDE) clinical trials were combined and retrospectively analyzed. In the 1-level trial ${ }^{27,28}$ (clinicaltrials.gov: NCT00667459), 280 nonrandomized patients were enrolled at 20 investigational sites and underwent 1-level CDA. The surgeries were performed between January and November 2005. The 280 CDA patients were compared to 265 historical control ACDF patients from a previous IDE study ${ }^{1}$ (clinicaltrials.gov: NCT00642876) with identical inclusion-exclusion criteria. The surgeries for that previous clinical trial were performed at 32 sites from October 2002 to August 2004. In the 2level randomized trial $^{8,29}$ (clinicaltrials.gov: NCT00637156), 209 patients underwent 2-level CDA, and 188 patients received 2-level ACDF in surgeries performed at 30 sites from June 2006 to November 2007.
The same device was used (PRESTIGE LP, Medtronic, Inc, Memphis, Tennessee) for the 1level and 2-level CDA surgeries. The same cortical ring allograft and anterior plate (Atlantis, Medtronic) was also used for both 1-level and 2-level ACDF standardized procedures.

\section{Sample}

To be included in one of these trials, patients had to have cervical degenerative disc disease at 1 or 2 adjacent levels involving intractable radiculopathy, myelopathy, or both. The presence of disc herniation and/or osteophyte responsible for nerve root and/or spinal cord compression had to be documented by patient history and radiographic studies.

\section{Clinical Outcomes}

As part of both protocols, patients completed the following questionnaires: the Neck Disability Index (NDI) ${ }^{30}$ the Medical Outcomes Study Short Form Health Survey (SF-36), ${ }^{31}$ and numerical rating scales (from 0 to 20 representing intensity + frequency of pain) for neck pain and arm pain. ${ }^{32}$

\section{Safety Outcomes}

Neurological function was assessed by physicianconducted tests of motor, sensory, and reflex functions. Neurological success was achieved by the maintenance or improvement from preoperative status. An adverse event (AE) was defined as any clinical adverse sign, symptom, syndrome, or illness that occurred or worsened during the operative and postoperative periods. The severity of each AE was graded according to World Health Organization criteria (grades 1-4: mild, moderate, severe, lifethreatening), and the association of each AE with the implant or surgical procedure was assessed by an independent Clinical Adjudication Committee. Secondary surgical interventions were classified as either revision (adjustment or modification of the implant), removal (removal of implant or some of its components), supplemental fixation (placement of additional devices), or reoperation (any reoperation that is not a revision, removal, or supplemental fixation).

\section{Overall Success}

Both protocols had overall success" as the primary end point. A patient was considered an overall success when all 4 of the following criteria 
were met: (1) NDI score improvement of $\geq 15$ points from preoperative score, (2) maintenance or improvement in neurological status from preoperative, (3) no serious AE caused by the implant or by both the implant and the surgical procedure, and (4) no additional surgery classified as supplemental fixation, revision, or nonelective implant removal.

\section{Heterotopic Ossification}

In 1-level and 2-level CDA subjects, $\mathrm{HO}$ was assessed on radiographs and graded according to the classification by Mehren et $\mathrm{al}^{33}: 0=$ no $\mathrm{HO}$ present, $\mathrm{I}=\mathrm{HO}$ detectable in front of the vertebral body but not in the anatomical interdiscal space, $\mathrm{II}=\mathrm{HO}$ growing in the disc space and possibly affecting the function of the prosthesis, III = bridging ossifications that still allow movement of the prosthesis, or IV = complete fusion of treated segment without movement in flexion or extension.

\section{Statistical Analyses}

Statistical analyses were conducted with Statistical Analysis System (SAS Institute, Inc, Cary, North Carolina). To adjust for any possible effects of demographic characteristics or preoperative measures on clinical outcomes, the propensity score technique was used. The propensity score was calculated based on a logistic regression model with the following covariates: age, height, weight, sex, race, marital status, education level, work status, workers' compensation, spinal litigation, tobacco use, alcohol use, nonnarcotic pain medication use, weak narcotic pain medication use, strong narcotic pain medication use, muscle relaxant medication use, time to onset of symptoms, and previous neck surgery as well as treatment level and preoperative scores for NDI, SF-36 Physical Component Summary (PCS), SF-36 Mental Component Summary (MCS), neck pain, arm pain, gait, foraminal compression test reaction, and neurological status (motor function, sensory, and reflex). Covariate balance after propensity score adjustment was examined by using analysis of covariance (ANCOVA).

The outcome comparisons between groups were performed with ANCOVA adjusting for propensity score. The cumulative probabilities of AEs and secondary surgeries were derived from the life-table method and compared by using the PHREG procedure adjusting for propensity score. Nominal $P$ values were reported without adjusting for
Table 1. Number of patients with overall success outcome data (percent follow-up) in the cervical disc arthroplasty (CDA) and anterior cervical discectomy and fusion (ACDF) groups.

\begin{tabular}{lcclll}
\hline & \multicolumn{2}{c}{ CDA } & & \multicolumn{2}{c}{ ACDF } \\
\cline { 2 - 3 } \cline { 6 - 6 } Number of Patients & 1-Level & 2-Level & & 1-Level & 2-Level \\
\hline Preoperative & $280(100)$ & $209(100)$ & & $265(100)$ & $188(100)$ \\
1-y postoperative & $274(97.9)$ & $202(96.7)$ & & $223(84.2)$ & $166(88.3)$ \\
2-y postoperative & $271(96.8)$ & $199(95.2)$ & & $220(83.0)$ & $160(85.1)$ \\
3-y postoperative & $241(86.1)$ & $185(88.5)$ & & $160(60.4)$ & $149(79.3)$ \\
5-y postoperative & $199(71.1)$ & $167(79.9)$ & & $188(70.9)$ & $138(73.4)$ \\
7-y postoperative & $211(75.4)$ & $154(73.7)$ & & $182(68.7)$ & $126(67.0)$
\end{tabular}

comparisons of multiple outcomes and treatment groups.

\section{RESULTS}

A total of 942 patients were allocated as 489 CDA (280 1-level and 209 2-level) and 453 ACDF (265 1-level and 188 2-level). Table 1 reports the number of patients with overall success outcome data at each follow-up interval. By 7 years, the follow-up rates were $75.4 \%$ for 1 -level CDA, $73.7 \%$ for 2-level CDA, $68.7 \%$ for 1-level ACDF, and $67.0 \%$ for 2-level ACDF. The demographic characteristics are reported in Table 2. There were no significant differences between the groups after adjusting for the propensity score. The surgical characteristics are reported in Table 3 . The operating time was statistically longer for 2-level than 1level surgery for both CDA and ACDF. Estimated blood loss was statistically higher for 2-level CDA than 1-level CDA but not different between 1-level and 2-level ACDF.

\section{Overall Success}

There were no statistical differences in the rates of overall success between 1-level and 2-level CDA at any follow-up interval or between 1-level and 2-level ACDF (Table 4). Further, none of the individual components of overall success were statistically different between 1-level and 2-level CDA or 1-level and 2-level ACDF, with the exception of neurological success at 3 years for CDA.

\section{Clinical Outcomes}

There were no statistical differences in any of the patient-reported outcomes at any of the follow-up intervals between 1-level and 2-level procedures for either CDA or ACDF (Figure 1). All 4 groups exhibited a significant improvement from their preoperative scores and maintained this improve- 
Table 2. Demographic characteristics: mean \pm standard deviation and number/total (percent) of patients.

\begin{tabular}{|c|c|c|c|c|c|c|c|c|}
\hline & \multicolumn{4}{|c|}{ CDA } & \multicolumn{4}{|c|}{ ACDF } \\
\hline & 1-Level & 2-Level & $\begin{array}{c}P \text { values, }{ }^{*} \\
\text { 1- vs 2-Level }\end{array}$ & $\begin{array}{c}\text { Adjusted } \\
P \text { values, } * * \\
\text { 1- vs } 2 \text {-Level }\end{array}$ & 1-Level & 2-Level & $\begin{array}{c}P \text { values, }{ }^{*} \\
\text { 1- vs 2-Level }\end{array}$ & $\begin{array}{c}\text { Adjusted } \\
P \text { values, } * * \\
\text { 1- vs } 2 \text {-Level } \\
\end{array}$ \\
\hline Age (y) & $44.5 \pm 8.8$ & $47.1 \pm 8.3$ & .001 & .962 & $43.9 \pm 8.8$ & $47.3 \pm 7.7$ & $<.001$ & .994 \\
\hline Male gender & $129 / 280(46.1)$ & $92 / 209(44.0)$ & .713 & .995 & $122 / 265(46.0)$ & 90/188 (47.9) & .704 & .999 \\
\hline BMI $\left(\mathrm{kg} / \mathrm{m}^{2}\right)$ & $28.5 \pm 5.6$ & $28.2 \pm 5.6$ & .598 & .916 & $28.3 \pm 5.1$ & $28.6 \pm 4.9$ & .578 & .881 \\
\hline Education & & & .003 & .96 & & & .033 & .989 \\
\hline Less than high school & $15 / 278(5.4)$ & 21/209 (10.0) & & & $14 / 264(5.3)$ & 20/188 (10.6) & & \\
\hline High school & $57 / 278(20.5)$ & $63 / 209(30.1)$ & & & $77 / 264(29.2)$ & $64 / 188(34.0)$ & & \\
\hline Above high school & $206 / 278(74.1)$ & $125 / 209(59.8)$ & & & $173 / 264(65.5)$ & $104 / 188(55.3)$ & & \\
\hline Working preoperatively & $188 / 280(67.1)$ & $146 / 209(69.9)$ & .556 & .992 & $166 / 265(62.6)$ & $113 / 188(60.1)$ & .624 & .999 \\
\hline Workers' compensation case & $32 / 280(11.4)$ & 26/209 (12.4) & .778 & .997 & $35 / 265(13.2)$ & 19/188 (10.1) & .378 & .996 \\
\hline Unresolved spinal ligation & $34 / 280(12.1)$ & 0/209(0.0) & $<.001$ & .937 & $32 / 265(12.1)$ & $1 / 188(0.5)$ & $<.001$ & .805 \\
\hline
\end{tabular}

Abbreviations: CDA, cervical disc arthroplasty; ACDF, anterior cervical discectomy and fusion; BMI, body mass index.

${ }^{*} P$ values without adjusting for the propensity score: comparison between groups (analysis of covariance for continuous variables and Fisher exact test for categorical variables). Values listed in bold font are statistically significant.

** $P$ values after adjusting for the propensity score: comparison between groups (analysis of covariance for continuous variables and logistic regression for categorical variables, with propensity score as covariate).

ment at all follow-ups. At 7 years, the CDA groups had the following score improvements compared to baseline for 1 and 2 levels, respectively: NDI (38.2 vs $39.0, P=0.768)$, neck pain (11.7 vs $12.3, P=0.374)$, arm pain (11.3 vs $11.0, P=0.736)$, SF-36 PCS (12.6 vs $14.5, P=0.220)$, and $\operatorname{MCS}(8.5$ vs 9.3 , $P=0.605)$. At 7 years, the ACDF groups had the following score improvements for 1-level and 2levels, respectively: NDI (31.1 vs $31.6, P=0.859$ ), neck pain (9.7 vs $9.9, P=0.796)$, arm pain (9.9 vs 10.1, $P=0.848)$, SF-36 PCS (10.8 vs 12.1, $P=0.424)$, and MCS (7.9 vs 7.6, $P=0.828$ ).

\section{Adverse Events}

There were no statistical differences in the rates of implant-related AEs or serious implant-related AEs between 1-level and 2-level CDA (Table 5). At longterm follow-up of 7 years, implant-related AE rates were $21.4 \%$ for 1 -level and $26.6 \%$ for 2 -level CDA, with rates of serious implant-related AEs of $6.5 \%$ and $3.2 \%$, respectively. Although the rate of implant-related AEs at 7 years was higher for 2level ACDF (27.7\%) than 1-level ACDF (18.9\%) $(P \leq .036)$, the rates of serious implant-related AEs between 1-level and 2-level ACDF did not differ (at
7 years, $5.6 \%$ and $7.2 \%$ for 1 - and 2-level, respectively) (Table 5).

\section{Secondary Surgeries}

The rate of secondary surgeries was not statistically different between the 1-level and 2-level procedures for either CDA or ACDF (Table 6). This was the case for secondary surgeries at the index and adjacent levels at both 2 years and 7 years. In fact, at long-term follow-up of 7 years, the rate of secondary surgeries at adjacent levels trended slightly lower for 2-level than 1-level CDA (11.6\% vs $6.5 \%, P \leq .056)$.

\section{$\mathrm{HO}$}

Table 7 shows occurrence of $\mathrm{HO}$ by grade at 2 and 7 years for 1-level and both superior and inferior levels of 2-level CDA. At 2 years, grade IV $\mathrm{HO}$ was reported in $1.2 \%$ of 1 -level CDA patients and $2.0 \%$ and $3.0 \%$ at the superior and inferior levels in 2-level CDA patients. At 7 years, the rates of grade IV HO were $4.6 \%$ for 1 -level and $8.6 \%$ and $7.3 \%$ for superior and inferior levels in 2-level CDA, respectively.

Table 3. Surgical characteristics: observed mean \pm standard deviation.

\begin{tabular}{|c|c|c|c|c|c|c|}
\hline & \multicolumn{3}{|c|}{ CDA } & \multicolumn{3}{|c|}{ ACDF } \\
\hline & 1-Level & 2-level & $\begin{array}{c}\text { Adjusted } P \text { values, }{ }^{*} \\
\text { 1- vs 2-Level }\end{array}$ & 1-Level & 2-Level & $\begin{array}{c}\text { Adjusted } P \text { values, } \\
\text { 1- vs 2-Level }\end{array}$ \\
\hline EBL (mL) & $50.5 \pm 73.5$ & $67.2 \pm 64.1$ & .017 & $57.5 \pm 68.1$ & $55.7 \pm 46.3$ & .998 \\
\hline Surgery time (h) & $1.5 \pm 0.6$ & $2.1 \pm 0.8$ & $<.001$ & $1.4 \pm 0.5$ & $1.7 \pm 0.7$ & $<.001$ \\
\hline
\end{tabular}

Abbreviations: CDA, cervical disc arthroplasty; ACDF, anterior cervical discectomy and fusion; EBL, estimated blood loss.

${ }^{*} P$ values after adjusting for the propensity score for comparisons between groups by using analysis of covariance with propensity score as the covariate. 
Table 4. Rates of overall success and its components: number/total (percent) of patients.

\begin{tabular}{|c|c|c|c|c|c|c|}
\hline & \multicolumn{3}{|c|}{ CDA } & \multicolumn{3}{|c|}{ ACDF } \\
\hline & 1-Level & 2-Level & $\begin{array}{c}\text { Adjusted } P \text { values, } \\
\text { 1- vs 2-Level }\end{array}$ & 1-Level & 2-Level & $\begin{array}{c}\text { Adjusted } P \text { values, } \\
\text { 1- vs } 2 \text {-Level }\end{array}$ \\
\hline $1-y:$ overall success & $226 / 274(82.5)$ & $167 / 202(82.7)$ & .409 & $150 / 223(67.3)$ & $117 / 166(70.5)$ & .415 \\
\hline NDI success & $241 / 272(88.6)$ & $183 / 202(90.6)$ & .263 & $176 / 222(79.3)$ & $136 / 165(82.4)$ & .221 \\
\hline Neurological success & $257 / 272(94.5)$ & $182 / 203(89.7)$ & .245 & $194 / 226(85.8)$ & $136 / 165(82.4)$ & .269 \\
\hline Second surgery failure & 8 & 2 & - & 9 & 9 & - \\
\hline Serious implant AE & 8 & 1 & - & 6 & 8 & - \\
\hline $2-y:$ overall success & $215 / 271(79.3)$ & $162 / 199(81.4)$ & .208 & $147 / 220(66.8)$ & $111 / 160(69.4)$ & .404 \\
\hline NDI success & $237 / 270(87.8)$ & $175 / 199(87.9)$ & .218 & $177 / 219(80.8)$ & $126 / 159(79.2)$ & .983 \\
\hline Neurological success & $252 / 270(93.3)$ & $182 / 199(91.5)$ & .499 & $184 / 220(83.6)$ & $137 / 159(86.2)$ & .187 \\
\hline Second surgery failure & 12 & 4 & - & 12 & 12 & - \\
\hline Serious implant AE & 11 & 2 & - & 10 & 11 & - \\
\hline 3-y: overall success & $200 / 241(83.0)$ & $151 / 185(81.6)$ & .729 & $103 / 160(64.4)$ & $105 / 149(70.5)$ & .329 \\
\hline NDI success & $216 / 239(90.4)$ & $166 / 185(89.7)$ & .968 & $127 / 159(79.9)$ & $121 / 147(82.3)$ & .659 \\
\hline Neurological success & $229 / 238(96.2)$ & $167 / 185(90.3)$ & .011 & $134 / 161(83.2)$ & $124 / 148(83.8)$ & .585 \\
\hline Second surgery failure & 14 & 6 & - & 15 & 12 & - \\
\hline Serious implant AE & 14 & 3 & - & 13 & 11 & - \\
\hline 5-y: overall success & $153 / 199(76.9)$ & $133 / 167(79.6)$ & .538 & $133 / 188(70.7)$ & $91 / 138(65.9)$ & .51 \\
\hline NDI success & $168 / 197(85.3)$ & $149 / 167(89.2)$ & .224 & $156 / 187(83.4)$ & $105 / 135(77.8)$ & .687 \\
\hline Neurological success & $186 / 196(94.9)$ & $151 / 167(90.4)$ & .194 & $162 / 189(85.7)$ & $119 / 136(87.5)$ & .654 \\
\hline Second surgery failure & 14 & 7 & - & 15 & 15 & - \\
\hline Serious implant AE & 14 & 4 & - & 14 & 13 & - \\
\hline 7-y: overall success & $158 / 211(74.9)$ & $121 / 154(78.6)$ & .332 & $115 / 182(63.2)$ & $79 / 126(62.7)$ & .951 \\
\hline NDI success & $179 / 208(86.1)$ & $134 / 154(87.0)$ & .561 & $145 / 181(80.1)$ & $93 / 123(75.6)$ & .731 \\
\hline Neurological success & $192 / 207(92.8)$ & $141 / 154(91.6)$ & .867 & $145 / 182(79.7)$ & $101 / 123(82.1)$ & .421 \\
\hline Second surgery failure & 16 & 7 & - & 15 & 16 & - \\
\hline Serious implant AE & 16 & 5 & - & 14 & 13 & - \\
\hline
\end{tabular}

Abbreviations: CDA, cervical disc arthroplasty; ACDF, anterior cervical discectomy and fusion; NDI, Neck Disability Index; AE, adverse event.

${ }^{*} P$ values from logistic regression adjusting for propensity score. Success status was determined in patients with no missing data for Oswestry Disability Index, neurological, and disc height outcomes in addition to including as failures those with additional surgery (revision, removal, supplemental fixation) or serious device or device/procedure-associated adverse events at any interval, whether missing other data or not.

\section{DISCUSSION}

The patient groups included in this post hoc analysis belonged to separate clinical trials but met similar inclusion/exclusion criteria and underwent the same CDA or ACDF treatments, with the primary difference being 1-level versus 2-level pathology and treatment. Statistical methods were used to control for possible differences in preoperative patient characteristics of the 2 different trial groups. No statistical differences were found between 1-level and 2-level CDA for any measured outcomes. No differences were found between 1level and 2-level ACDF for overall success, all patient-reported outcomes, and secondary surgeries at the index and adjacent levels. Compared to 1level ACDF, 2-level ACDF had an increase in implant-related AEs at 7 years.

\section{Patient-Reported Outcomes}

Consistent with the results of the present study, other studies have reported noninferiority and sometimes superiority of patient-reported outcomes for multilevel CDA compared to single-level CDA. ${ }^{21,22,24,26,34,35}$ The current study found no statistical differences between the patient-reported outcomes of 1-level and 2-level ACDF. This is consistent with the results of Lee et $\mathrm{al}^{36}$ but different from the comparison of the ACDF arms of the Mobi-C clinical trials, ${ }^{25,26}$ which reported a decrease in NDI, PCS, and overall success for 2-level ACDF compared to 1-level ACDF.

\section{Safety Outcomes}

Studies have previously reported no increase in AEs or secondary surgeries with increasing CDA levels of treatment. ${ }^{24,26,34,35}$ Similarly, the comparison of the ACDF arms of the Mobi-C clinical trials found no difference in AEs or in secondary surgery rates between 1-level and 2-level ACDF. ${ }^{25,26}$ This is in contrast to Veeravagu et $\mathrm{al},{ }^{18}$ who found that multilevel ACDF patients had an increased rate of reoperations. It is important to note that this latter study relied on an administrative database while the surgical procedures compared between the ACDF arms were standardized. The current study did not find a difference in the rate of secondary surgeries but found that 2-level ACDF appeared to have a higher rate of implant-related AEs at 7 years than 1level ACDF. 
1-Level Versus 2-Level Treatment With Cervical Disc Arthroplasty or Fusion

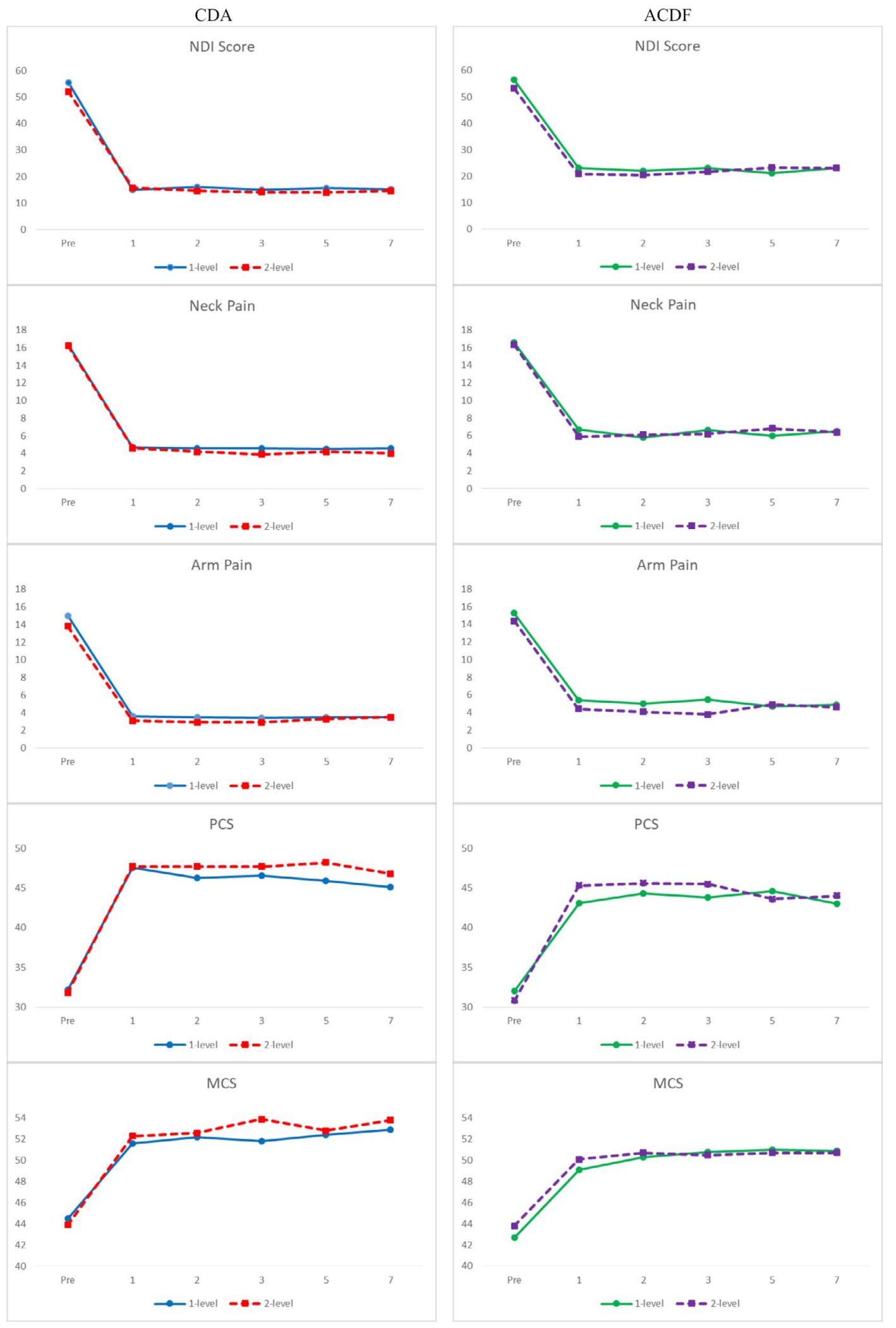

Figure 1. Mean of patient-reported scores: observed means for preoperative scores and adjusted means by propensity score for postoperative scores. 
Table 5. Implant-related adverse events: number (percent) of patients.

\begin{tabular}{|c|c|c|c|c|c|c|}
\hline & \multicolumn{3}{|c|}{ CDA } & \multicolumn{3}{|c|}{$\mathrm{ACDF}$} \\
\hline & 1-Level & 2-Level & $\begin{array}{c}\text { Adjusted } P \text { values, } \\
\text { 1- vs } 2 \text {-Level }\end{array}$ & 1-Level & 2-Level & $\begin{array}{c}\text { Adjusted } P \text { values, } \\
\text { 1- vs } 2 \text {-Level }\end{array}$ \\
\hline \multicolumn{7}{|l|}{$2-\mathrm{y}$} \\
\hline Implant-related AEs & $34(12.3)$ & $33(16.1)$ & .054 & $41(16.9)$ & $39(21.1)$ & .067 \\
\hline Serious implant-related AEs & $13(4.7)$ & $4(2.0)$ & .289 & $14(5.6)$ & $12(6.5)$ & .263 \\
\hline \multicolumn{7}{|l|}{$7-y$} \\
\hline Implant-related AEs & $49(21.4)$ & $48(26.6)$ & .067 & 44 (18.9) & $46(27.7)$ & .036 \\
\hline Serious implant-related AEs & $17(6.5)$ & $5(3.2)$ & .127 & $14(5.6)$ & $13(7.2)$ & .159 \\
\hline
\end{tabular}

Abbreviations: CDA, cervical disc arthroplasty; ACDF, anterior cervical discectomy and fusion; AEs, adverse events.

${ }^{*} P$ values are obtained from the PHREG procedure using the likelihood ratio method adjusting for the propensity score. Cumulative probabilities are from the life-table estimation.

One possible limitation of this study is that comparisons were made across separate clinical trials. The authors believe, however, that the statistical propensity score technique has provided sufficient control of confounding variables to present with confidence the results and conclusions of this study. The availability of certain data may limit the comparability of the present study to the results of other studies. Specifically, the current study did not measure either pseudarthrosis or adjacent segment degeneration in ACDF patients. Zigler et $\mathrm{al}^{25}$ reported that the 6-month and 12month rate of nonunion was higher for 2-level ACDF than 1-level ACDF. This is consistent with previously reported higher pseudarthrosis rates with multilevel ACDF. ${ }^{37-39}$ Zigler et $\mathrm{al}^{25}$ also found no statistical difference in adjacent segment degeneration between 1-level and 2-level ACDF. To date, there is no conclusive evidence of the influence of number of fused cervical levels on adjacent segment degeneration. ${ }^{40}$
Clinical trials, in general, have established CDA as a safe and effective alternative to ACDF in the treatment of cervical degenerative disease. The original 1-level IDE trial of the studied device reported similar improvement for CDA and ACDF at 2- and 7-year follow-up but with a statistically greater proportion of CDA patients achieving overall success (a composite endpoint of safety/efficacy) than ACDF patients at both 2-year and 7-year follow-up (74.9\% CDA vs $63.2 \%$ ACDF). ${ }^{27,28}$ Similarly, the 2level IDE trial also reported overall success superiority for CDA at 2-year $(81.4 \%$ vs $69.4 \%)$ and 7 -year follow-up (78.6\% vs $62.7 \%) .{ }^{8,29}$ At 7 years, 2-level CDA also had fewer serious implant-related AEs $(3.2 \%$ vs $7.2 \%)$ and fewer secondary surgeries at the index level (4.2\% vs $14.7 \%)$ than 2-level ACDF. In addition to IDE clinical trials, evidence for the safety and effectiveness of multilevel CDA has also accumulated through studies comparing multilevel CDA to 1-level $\mathrm{CDA}^{22,24,34,35,41-44}$ and to multilevel

Table 6. Secondary surgeries: number (percent) of patients.

\begin{tabular}{|c|c|c|c|c|c|c|}
\hline & \multicolumn{3}{|c|}{ CDA } & \multicolumn{3}{|c|}{ ACDF } \\
\hline & 1-Level & 2-Level & $\begin{array}{c}\text { Adjusted } P \text { values, }{ }^{*} \\
\text { 1- vs 2-Level }\end{array}$ & 1-Level & 2-Level & $\begin{array}{c}\text { Adjusted } P \text { values, } \\
\text { 1- vs 2-Level }\end{array}$ \\
\hline 2-y total secondary surgeries at index level & $14(5.1)$ & $5(2.5)$ & 0.509 & $19(7.9)$ & $15(8.6)$ & .455 \\
\hline Revision surgeries & $1(0.4)$ & $0(0.0)$ & .424 & $4(1.6)$ & $1(0.5)$ & .678 \\
\hline Removal surgeries & $10(3.6)$ & $3(1.5)$ & .688 & $8(3.3)$ & $6(3.4)$ & .51 \\
\hline Elective removal surgeries & - & - & - & $4(1.7)$ & $2(1.2)$ & .663 \\
\hline Supplemental fixation surgeries & $2(0.7)$ & $1(0.5)$ & .786 & $3(1.3)$ & $3(1.7)$ & .62 \\
\hline Reoperations & $3(1.1)$ & $2(1.0)$ & .563 & $2(0.8)$ & $4(2.3)$ & .106 \\
\hline 7-y total secondary surgeries at index level & $18(7.3)$ & $8(4.2)$ & .566 & $29(13.6)$ & $22(14.7)$ & .631 \\
\hline Revision surgeries & $1(0.4)$ & $0(0.0)$ & .424 & $5(2.1)$ & $1(0.5)$ & .487 \\
\hline Removal surgeries & $14(5.8)$ & $6(3.2)$ & .746 & $8(3.3)$ & $6(3.4)$ & .51 \\
\hline Elective removal surgeries & - & - & - & $13(6.9)$ & $6(4.3)$ & .225 \\
\hline Supplemental fixation surgeries & $2(0.7)$ & $1(0.5)$ & .786 & $5(2.3)$ & $7(5.5)$ & .065 \\
\hline Reoperations & $3(1.1)$ & $3(1.6)$ & .247 & $4(2.9)$ & $5(3.1)$ & .3 \\
\hline \multicolumn{7}{|c|}{ Secondary surgeries involved with adjacent level } \\
\hline 2-y postoperative & $6(2.2)$ & $5(2.5)$ & .916 & $10(4.2)$ & $6(3.4)$ & .58 \\
\hline 7 -y postoperative & $27(11.6)$ & $12(6.5)$ & .056 & $22(10.9)$ & $17(12.5)$ & .366 \\
\hline
\end{tabular}

Abbreviations: CDA, cervical disc arthroplasty; ACDF, anterior cervical discectomy and fusion.

$* P$ values are obtained from the PHREG procedure using the likelihood ratio method adjusting for the propensity score. Cumulative probabilities are from the life-table estimation. 
Table 7. Heterotopic ossification: number/total (percent) of patients.

\begin{tabular}{lccc}
\hline & & \multicolumn{2}{c}{ 2-Level CDA } \\
\cline { 3 - 4 } & 1-Level CDA & Superior Level & Inferior Level \\
\hline 2-y & & & \\
Grade I & $45 / 260(17.3)$ & $10 / 198(5.1)$ & $11 / 198(5.6)$ \\
Grade II & $40 / 260(15.4)$ & $13 / 198(6.6)$ & $22 / 198(11.1)$ \\
Grade III & $23 / 260(8.8)$ & $28 / 198(14.1)$ & $33 / 198(16.7)$ \\
Grade IV & $3 / 260(1.2)$ & $4 / 198(2.0)$ & $6 / 198(3.0)$ \\
7-y & & & \\
Grade I & $26 / 195(13.3)$ & $7 / 151(4.6)$ & $12 / 151(7.9)$ \\
Grade II & $43 / 195(22.1)$ & $18 / 151(11.9)$ & $26 / 151(17.2)$ \\
Grade III & $31 / 195(15.9)$ & $39 / 151(25.8)$ & $38 / 151(25.2)$ \\
Grade IV & $9 / 195(4.6)$ & $13 / 151(8.6)$ & $11 / 151(7.3)$ \\
\hline
\end{tabular}

Abbreviation: CDA, cervical disc arthroplasty.

ACDF ${ }^{45-47}$ Meta-analyses have confirmed the safety and effectiveness of multilevel arthroplasty. ${ }^{23,48}$

The current study, using data from highly similar clinical trials and with strong statistical control for possible differences in key preoperative subject characteristics between clinical trials, provides additional evidence suggesting that 1 - and 2-level procedures provide similar efficacy and safety outcomes for patients being treated for cervical disc disease for both CDA and ACDF. These results are consistent with the majority of prior literature.

\section{CONCLUSIONS}

The present study determined that patients undergoing surgery for cervical disc disease at 2 adjacent cervical levels report similar improvement to patients undergoing surgery at just 1 cervical level after either CDA or ACDF. Safety profiles were also not significantly different between 1- and 2-level procedures, with just 1 exception: compared to 1level ACDF, 2-level ACDF had a greater proportion of device-related AEs at longer-term follow-up, though the difference between 1- and 2-level ACDF in serious device-related AEs was not significant.

\section{REFERENCES}

1. Mummaneni P, Burkus JK, Haid RW, et al. Clinical and radiographic analysis of cervical disc arthroplasty compared with allograft fusion: a randomized controlled clinical trial. $J$ Neurosurg Spine. 2007;6:198-209.

2. Heller JG, Sasso RC, Papadopoulos SM, et al. Comparison of BRYAN cervical disc arthroplasty with anterior cervical decompression and fusion: clinical and radiographic results of a randomized, controlled, clinical trial. Spine. 2009;34:101-107.

3. Murrey D, Janssen M, Delamarter R, et al. Results of the prospective, randomized, controlled multicenter Food and Drug Administration investigational device exemption study of the ProDisc-C total disc replacement versus anterior discectomy and fusion for the treatment of 1-level symptomatic cervical disc disease. Spine J. 2009;9:275-286.

4. Coric D, Nunley PD, Guyer RD, et al. Prospective, randomized, multicenter study of cervical arthroplasty: 269 patients from the Kineflex $\mid \mathrm{C}$ artificial disc investigational device exemption study with a minimum 2-year follow-up: clinical article. J Neurosurg Spine. 2011;15:348-358.

5. Phillips FM, Lee JY, Geisler FH, et al. A prospective, randomized, controlled clinical investigation comparing PCM cervical disc arthroplasty with anterior cervical discectomy and fusion: 2-year results from the US FDA IDE clinical trial. Spine. 2013;38:E907-E918.

6. Hisey MS, Bae HW, Davis R, et al. Multi-center, prospective, randomized, controlled investigational device exemption clinical trial comparing Mobi-C Cervical Artificial Disc to anterior discectomy and fusion in the treatment of symptomatic degenerative disc disease in the cervical spine. Int J Spine Surg. 2014;8.

7. Davis RJ, Kim KD, Hisey MS, et al. Cervical total disc replacement with the Mobi-C cervical artificial disc compared with anterior discectomy and fusion for treatment of 2-level symptomatic degenerative disc disease: a prospective, randomized, controlled multicenter clinical trial: clinical article. $J$ Neurosurg Spine. 2013;19:532-545.

8. Gornet MF, Lanman TH, Burkus JK, et al. Cervical disc arthroplasty with the Prestige LP disc versus anterior cervical discectomy and fusion, at 2 levels: results of a prospective, multicenter randomized controlled clinical trial at 24 months. $J$ Neurosurg Spine. 2017:1-15.

9. Davis RJ, Nunley PD, Kim KD, et al. Two-level total disc replacement with Mobi-C cervical artificial disc versus anterior discectomy and fusion: a prospective, randomized, controlled multicenter clinical trial with 4-year follow-up results. $J$ Neurosurg Spine. 2015;22:15-25.

10. Radcliff K, Coric D, Albert T. Five-year clinical results of cervical total disc replacement compared with anterior discectomy and fusion for treatment of 2-level symptomatic degenerative disc disease: a prospective, randomized, controlled, multicenter investigational device exemption clinical trial. J Neurosurg Spine. 2016;25:213-224.

11. Eck JC, Humphreys SC, Lim TH, et al. Biomechanical study of the effects of cervical spine fusion on adjacent-level intradiscal pressure and segmental motion. Spine. 2002;27:24312434.

12. Lopez-Espina CG, Amirouche F, Havalad V. Multilevel cervical fusion and its effect on disc degeneration and osteophyte formation. Spine. 2006;31:972-978.

13. Park DH, Ramakrishnan P, Cho TH, et al. Effect of lower two-level anterior cervical fusion on the superior adjacent level. J Neurosurg Spine. 2007;7:336-340.

14. Hilibrand AS, Robbins M. Adjacent segment degeneration and adjacent segment disease: the consequences of spinal fusion? Spine J. 2004;4:190S-194S.

15. Goffin J, Geusens E, Vantomme N, et al. Long-term follow-up after interbody fusion of the cervical spine. $J$ Spinal Disord Tech. 2004;17:79-85.

16. Sun Y, Zhao YB, Pan SF, et al. Comparison of adjacent segment degeneration five years after single level cervical fusion and cervical arthroplasty: a retrospective controlled study. Chin Med J (Engl). 2012;125:3939-3941.

17. Swank ML, Lowery GL, Bhat AL, et al. Anterior 
cervical allograft arthrodesis and instrumentation: multilevel interbody grafting or strut graft reconstruction. Eur Spine J. 1997;6:138-143.

18. Veeravagu A, Cole T, Jiang B, et al. Revision rates and complication incidence in single- and multilevel anterior cervical discectomy and fusion procedures: an administrative database study. Spine J. 2014;14:1125-1131.

19. Thaler M, Hartmann S, Gstottner M, et al. Footprint mismatch in total cervical disc arthroplasty. Eur Spine J. 2013;22:759-765.

20. Wu TK, Wang BY, Meng Y, et al. Multilevel cervical disc replacement versus multilevel anterior discectomy and fusion: a meta-analysis. Medicine. 2017;96:e6503.

21. Wu JC, Huang WC, Tsai HW, et al. Differences between 1- and 2-level cervical arthroplasty: more heterotopic ossification in 2-level disc replacement. J Neurosurg Spine. 2012;16:594-600.

22. Wu JC, Huang WC, Tsai TY, et al. Multilevel arthroplasty for cervical spondylosis: more heterotopic ossification at 3 years of follow-up. Spine. 2012;37:E1251-E1259.

23. Kepler CK, Brodt ED, Dettori JR, et al. Cervical artificial disc replacement versus fusion in the cervical spine: a systematic review comparing multilevel versus single-level surgery. Evid Based Spine Care J. 2012;3:19-30.

24. Bae HW, Kim KD, Nunley PD, et al. Comparison of clinical outcomes of 1- and 2-level total disc replacement: fouryear results from a prospective, randomized, controlled, multicenter IDE clinical trial. Spine. 2015;40:759-766.

25. Zigler JE, Rogers RW, Ohnmeiss DD. Comparison of 1level versus 2-level anterior cervical discectomy and fusion: clinical and radiographic follow-up at 60 months. Spine (Phila Pa 1976). 2016;41:463-469.

26. Bae HW, Nunley PD, Davis RJ, et al. One-level vs. twolevel treatment for cervical total disc replacement and anterior cervical discectomy and fusion at 7-year follow-up. Paper presented at: International Meeting on Advanced Spine Techniques; July 15, 2016; Washington, DC.

27. Gornet MF, Burkus JK, Shaffrey ME, et al. Cervical disc arthroplasty with PRESTIGE LP disc versus anterior cervical discectomy and fusion: a prospective, multicenter investigational device exemption study. J Neurosurg Spine. 2015:1-16.

28. Gornet MF, Burkus JK, Shaffrey ME, et al. Cervical disc arthroplasty with Prestige LP disc versus anterior cervical discectomy and fusion: seven-year outcomes. Int J Spine Surg. 2016;10:24.

29. Lanman TH, Burkus JK, Dryer RG, et al. Long-term clinical and radiographic outcomes of the Prestige LP artificial cervical disc replacement at 2 levels: results from a prospective randomized controlled clinical trial. J Neurosurg Spine. 2017:113.

30. Vernon H, Mior S. The Neck Disability Index: a study of reliability and validity. $J$ Manipulative Physiol Ther. 1991;14:409-415.

31. Ware JE, Kosinski M, Keller SK, eds. SF-36 Physical and Mental Health Summary Scales: A User'-s Manual. Boston, MA: The Health Institute; 1994.

32. McDowell I, Newell C. Measuring Health: A Guide to Rating Scales and Questionnaires. New York: Oxford University Press; 1996.

33. Mehren C, Suchomel P, Grochulla F, et al. Heterotopic ossification in total cervical artificial disc replacement. Spine (Phila Pa 1976). 2006;31:2802-2806.

34. Huppert J, Beaurain J, Steib JP, et al. Comparison between single- and multi-level patients: clinical and radiological outcomes 2 years after cervical disc replacement. Eur Spine J. 2011;20:1417-1426.

35. Pimenta L, McAfee PC, Cappuccino A, et al. Superiority of multilevel cervical arthroplasty outcomes versus single-level outcomes: 229 consecutive PCM prostheses. Spine (Phila Pa 1976). 2007;32:1337-1344.

36. Lee SH, Lee JC, Tauchi R, et al. Influence of the number of cervical fusion levels on cervical spine motion and healthrelated quality of life. Spine (Phila Pa 1976). 2016;41:E474E480.

37. Frenkel MB, Cahill KS, Javahary RJ, et al. Fusion rates in multilevel, instrumented anterior cervical fusion for degenerative disease with and without the use of bone morphogenetic protein. J Neurosurg Spine. 2013;18:269-273.

38. Bolesta MJ, Rechtine GR II, Chrin AM. Three- and four-level anterior cervical discectomy and fusion with plate fixation: a prospective study. Spine (Phila Pa 1976). 2000;25:2040-2044; discussion 5-6.

39. Wright IP, Eisenstein SM. Anterior cervical discectomy and fusion without instrumentation. Spine (Phila Pa 1976). 2007;32:772-774; discussion 5.

40. Lawrence BD, Hilibrand AS, Brodt ED, et al. Predicting the risk of adjacent segment pathology in the cervical spine: a systematic review. Spine (Phila Pa 1976). 2012;37:S52-S64.

41. Kim HK, Kim MH, Cho DS, et al. Surgical outcome of cervical arthroplasty using Bryan. J Korean Neurosurg Soc. 2009;46:532-537.

42. Cardoso MJ, Rosner MK. Multilevel cervical arthroplasty with artificial disc replacement. Neurosurg Focus. 2010;28:E19.

43. Goffin J, van Loon J, Van Calenbergh F, et al. A clinical analysis of 4- and 6-year follow-up results after cervical disc replacement surgery using the Bryan Cervical Disc Prosthesis. $J$ Neurosurg Spine. 2010;12:261-269.

44. Tu TH, Wu JC, Huang WC, et al. Heterotopic ossification after cervical total disc replacement: determination by CT and effects on clinical outcomes. J Neurosurg Spine. 2011;14:457-465.

45. Kim SW, Limson MA, Kim SB, et al. Comparison of radiographic changes after ACDF versus Bryan disc arthroplasty in single and bi-level cases. Eur Spine J. 2009;18:218-231.

46. Fay LY, Huang WC, Tsai TY, et al. Differences between arthroplasty and anterior cervical fusion in two-level cervical degenerative disc disease. Eur Spine J. 2014;23:627-634.

47. Cheng L, Nie L, Zhang L, et al. Fusion versus Bryan Cervical Disc in two-level cervical disc disease: a prospective, randomised study. Int Orthop. 2009;33:1347-1351.

48. Joaquim AF, Riew KD. Multilevel cervical arthroplasty: current evidence. A systematic review. Neurosurg Focus. 2017;42:E4.

Disclosures and COI: The institutional review board for the clinical trials was Western Institutional Review Board (1-level study: Protocol 20050083, Study 1064723; 2-level study: Protocol 20060636, Study 1078218). The authors report the 
following potential or perceived conflicts: MF Gornet: Consulting: Aesculap and Medtronic; Stock Ownership: Bonovo, International Spine \& Orthopedic Institute, LLC, Nocimed, OuroBoros, Paradigm Spine; Royalties: Medtronic and RTI. TH Lanman: Consulting: Medtronic, Nuvasive, Stryker; Royalites: Stryker, Medtronic. J.K. Burkus: Consulting: Medtronic and Zimmer-Biomet; Royalties: Zimmer-Biomet; Research Support: Medtronic and Nuvasive. SD Hodges: Consulting: Medtronic. JR McConnell: Consulting: Globus Medical, DePuy/ Synthes, IMSE; Royalties: Globus Medical; Stock Ownership: Globus Medical; Speakers Bureau: Globus Medical, Zimmerman Biomet. RG Dryer: Consulting: Royalties: Nuvasive and Globus Med- ical. FW Schranck: Stock Ownership: Nocimed. AG Copay: None to declare.

Corresponding Author: Matthew F. Gornet, MD, The Orthopedic Center of St Louis, 14825 N. Outer Forty Rd., Suite 200, St Louis, MO 63017. Phone: (314) 324-5482; Email: mfgspine@gmail. com.

Published 31 December 2019

This manuscript is generously published free of charge by ISASS, the International Society for the Advancement of Spine Surgery. Copyright (C) 2019 ISASS. To see more or order reprints or permissions, see http://ijssurgery.com. 